\title{
Epidemiologia do dengue em Salvador-Bahia,1995-1999
}

\author{
Epidemiology of dengue in Salvador-Bahia, 1995-1999
}

\author{
Maria da Glória Teixeira', Maria da Conceição Nascimento Costa', Maurício Lima Barreto' \\ e Florisneide R. Barreto ${ }^{2}$
}

\begin{abstract}
Resumo Desde 1981, o Brasil tem registrado epidemias de dengue de grande magnitude e atualmente circulam simultaneamente dois sorotipos DEN-1 e DEN-2, em mais de 2.700 municípios. Em Salvador - Bahia, situada na Região Nordeste do país, ocorreram duas epidemias nos anos de 1995 e 1996, e posterior endemização da doença. Este estudo analisa a incidência desta virose nesse município, no período de 1995 a 1999, considerando entre outras variáveis, sua distribuição nos Distritos Sanitários e a situação de densidade do Aedes aegypti. Utiliza como fonte de dados registros oficiais de notificação e do programa de combate vetorial da cidade. A taxa de incidência de dengue foi de 691,4 e 393,5 por 100.000 habitantes, respectivamente, em 1995 e 1996, reduziu-se para 65 por 100.000 em 1998. Nos Distritos Sanitários mais carentes, este indicador alcançou valores superiores a 800 por 100.000 habitantes. O Índice de Infestação Predial pelo Aedes chegou a atingir 54,1\% em um dos seus bairros. Considerando a importância da reemergência do dengue no mundo os autores discutem os possíveis fatores que condicionaram a introdução do vírus, as suas apresentações epidemiológicas no curso de 4 anos, e a efetividade do programa de combate vetorial.
\end{abstract}

Palavras-chaves:Dengue. Epidemiologia. Aedes aegypti. Epidemia.

Abstract Since 1981, Brazil has registered dengue epidemic and simultaneous circulation of the DEN-1 and DEN-2 serotypes in over 2,700 municipalities. In Salvador- Bahia, located in the Northeastern region of the Country, two epidemic outbreaks occurred in the years of 1995 and 1996, with further endemic spread of the disease. This study analyses the incidence of the virosis within this municipal area, from 1995 to 1999, considering, among other variables, its distribution in the Sanitary Districts and density of Aedes aegypti. Registers of notified cases and the city's Vectorial Control Program were used as data source. The incidence rate of notified cases of dengue in 1995 and 1996, which were 691.4 and 393.5 per 100,000 inhabitants, respectively, decreased to 65 per 100,000 inhabitants in 1998. In the poorer Sanitary Districts, this index reached figures of over 800 per 100,000 inhabitants. The Premise Index for Aedes aegypti reached $54.1 \%$ in one of the Districts. Bearing in mind the relevance of the re-emergence of dengue in the world, the authors discuss the possible factors which condition the virus introduction, its epidemiological presentation over the course of four years, and the effectiveness of the vectorial combat (eradication) program.

Key-words: Dengue. Epidemiology. Aedes aegypti. Epidemic.

O dengue é uma infecção reemergente que vem preocupando as autoridades sanitárias de todo o mundo em virtude de sua circulação nos cinco continentes e grande potencial para causar formas graves e letais. No período compreendido entre 1955 e 1995 foram registrados cerca de 3 milhões de casos de febre hemorrágica do dengue e 58 mil mortes $^{7}$.

No Brasil, desde 1981 vem ocorrendo epidemias de dengue clássico e atualmente os sorotipos DEN1 e DEN-2 circulam em milhares de municípios. A febre hemorrágica do dengue vem sendo diagnosticada desde 1990, e até 1999 o número de notificações era de $888 \mathrm{com} 39$ óbitos $^{19}$.
$\mathrm{Na}$ Bahia, a primeira epidemia de dengue foi detectada em fevereiro de 1987 em Ipupiara, pequeno município do Sudoeste do Estado. O sorotipo identificado foi o DEN-1 e cerca de 623 casos foram notificados como suspeitos, correspondendo a uma taxa de incidência em torno de 24.000 casos por 100.000 habitantes. Em 90 dias, o vetor foi completamente eliminado e o vírus deixou de circular ${ }^{21}$. O dengue só voltou a ser detectado na Bahia em 1994, quando o DEN-2 foi introduzido em uma cidade do extremo Sul do Estado, disseminando-se em seguida. O maior pico epidêmico ocorreu em 1996, quando a incidência atingiu 502 por 100.000 habitantes. A seguir, observou-se um

\footnotetext{
1. Instituto de Saúde Coletiva da Universidade Federal da Bahia. 2. Curso de Pós-Graduação em Saúde Coletiva do Instituto de Saúde Coletiva da Universidade Federal da Bahia, Salvador, BA.

Endereço para correspondência: Dra. Maria da Glória Teixeira. Hospital Pediátrico. R. Padre Feijó, 29/40 andar Canela, 40110-170 Salvador, BA. Tel: 55 71 245-0544; Fax: 55 71 237-5856

e-mail: magloria @ufba.br

Recebido para publicação em 2/8/2000.
} 
declínio e, em 1998, esta taxa foi de 170 por 100.000 habitantes ${ }^{1}$. Entre 1994 a 1996 o único sorotipo isolado foi o DEN-2 e, somente em 1997 o DEN-1 também passou a circular intensamente.

Na Bahia são escassos os estudos epidemiológicos sobre este problema apesar da importância da reemergência deste vírus. A circulação simultânea de dois sorotipos está estabelecendo as condições concretas para ocorrência de formas graves desta doença. Neste sentido, este artigo tem como objetivo analisar a ocorrência do dengue e a situação de densidade e dispersão do Aedes aegypti, seu principal transmissor, em Salvador, capital deste Estado.

\section{MATERIAL E MÉTODOS}

Salvador é a terceira maior cidade brasileira em população, estimada em torno de 2.307.797 habitantes, em 1997, situada na Região Nordeste do Brasil.

O presente estudo foi desenvolvido com dados secundários referentes ao período de 1995 a 1999 , provenientes do Sistema Nacional de Agravos de Notificação (SINAN) da Secretaria Estadual de Saúde ${ }^{10}$ (SESAB), dos relatórios do programa de combate vetorial desenvolvido pelo Centro de Controle de Zoonoses da Secretaria Municipal de Saúde (CCZ/SMS) de Salvador ${ }^{15} 16$, em articulação com a Coordenação Regional da Fundação Nacional de Saúde/BAe do Projeto Piloto para erradicação do Aedes aegypti de Salvador/ Bahia ${ }^{8}$.

Dos dados do SINAN que são coletados rotineiramente pelas unidades de saúde da rede de serviços da cidade, foram selecionados aqueles relativos à identificação dos indivíduos, endereço e semana epidemiológica de início dos sintomas da doença.

Dos relatórios trimestrais do CCZ/SMS, que incluem dados das atividades desenvolvidas pelo Programa de Erradicação do Aedes aegypti no Município, foram levantadas informações acerca do número de bairros onde se desenvolvem as ações do programa e os valores dos índices de infestação predial (IIP), que foram obtidos no período de 1997 a 1999.

As estimativas populacionais, total e por faixas etárias, empregadas como denominadores para o cálculo dos indicadores de ocorrência da doença foram fornecidas pelo Departamento de Informação e Comunicação Social da SESAB.

Os dados do SINAN foram exportados para o Epiinfo versão 6.0, procedendo-se a limpeza no banco para exclusão de duplicidade de registros. Os valores dos índices de infestação predial foram digitados em planilha Excel, versão 97, estimando-se a seguir as suas médias e medianas, para os anos de referência deste estudo. A análise dos dados foi efetuada a partir das freqüências absolutas, percentuais e taxas de incidência da doença. O qui-quadrado foi o teste estatístico empregado para verificar a diferença nas incidências da doença em dois grupos etários (<15 e $\geq 15$ anos), admitindo-se um nível de significância de 0,05.

\section{RESULTADOS}

Em 1995 e 1996, foram registrados respectivamante 15.458 e 10.988 casos de dengue no município de Salvador, correspondendo a 691,4 e 393,5 notificações por 100 mil habitantes, verificando-se a seguir uma considerável redução desta taxa (Tabela 1). Observa- se na Figura 1, que o maior pico da primeira alça epidêmica de 1995 ocorreu na semana epidemiológica 18 (abril), quando a incidência semanal atingiu 75,1 por 100 mil habitantes, e até o final deste mês cerca de 8.500 casos já haviam sido registrados. A partir de maio,

Tabela 1 - Número de casos de dengue e incidência anual por 100.000 habitantes. Salvador-Bahia, 1995 - 1999*.

\begin{tabular}{lrc}
\hline Ano & \multicolumn{1}{c}{$N^{\circ}$} & Incidência \\
\hline 1995 & 15.458 & 691,37 \\
1996 & 10.988 & 393,50 \\
1997 & 1.256 & 44,59 \\
1998 & 1.478 & 64,99 \\
$1999^{*}$ & 608 & 16,20 \\
\hline
\end{tabular}

Fonte: SESAB/DIVEP

*Dados preliminares até a semana 42.

houve uma brusca redução da curva que se acentua no final de junho quando a incidência semanal decresceu para 7,1 casos por 100 mil habitantes. Nas duas primeiras semanas do mês de julho registra-se uma elevação (23,2 casos por 100 mil habitantes) e a incidência volta a patamares semelhantes ao mês de maio que eram em torno de 27 por 100 mil habitantes.
A partir deste período, delineia-se uma tendência consistente de redução até a semana epidemiológica 45, que corresponde ao início do mês de novembro daquele ano. Nas últimas semanas de 1995, verificamse discretas elevações de incidência, quando comparadas ao período anterior (de julho até a segunda semana de novembro). 


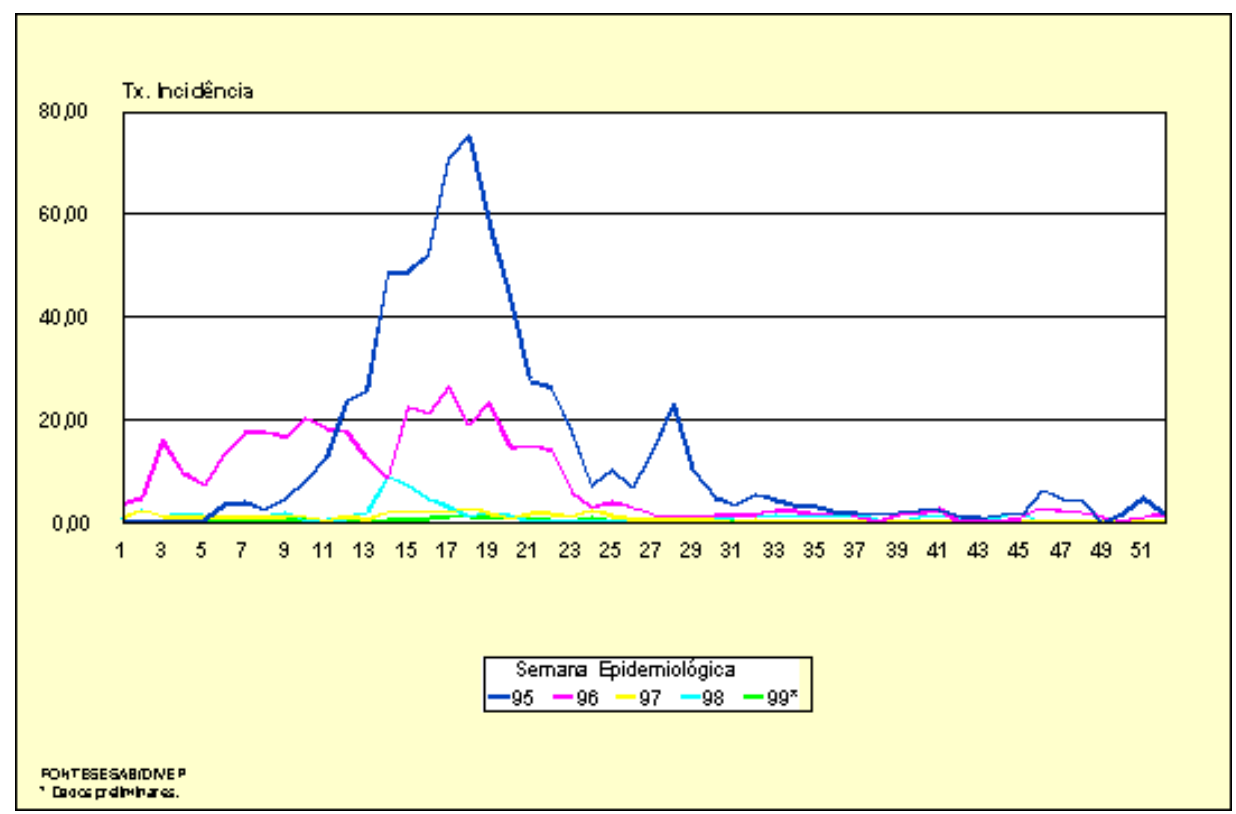
Figura 1 - Taxa de incidência de dengue (por 100.000 hab) por semana epidemiológica. Salvador-
Bahia, 1995-1999.

Em 1996, ocorre uma nova onda epidêmica em Salvador, que em janeiro atinge 1.158 casos, e já nos quatro primeiros meses totaliza 7.095 dos 10.988 registros daquele ano. O maior pico ocorreu entre os meses de abril e maio, alcançando na semana epidemiológica 17 o valor máximo de 26,3 casos por 100 mil habitantes. No segundo semestre deste ano também se observa uma queda progressiva da curva epidêmica que mostra discretas elevações nas semanas epidemiológicas 41, 46 e 47.

No ano seguinte, a taxa de incidência de dengue em Salvador reduziu-se drasticamente, quando comparada a dos dois anos anteriores, ocorrendo apenas 1.256 notificações $(44,6$ casos por 100.000 habitantes). A mais alta taxa de incidência em 1997 foi de 2,9 por 100.000 habitantes na semana epidemiológica 18. Mesmo com a redução de ocorrência da doença pode-se observar que no segundo semestre as taxas de incidência foram menores que no primeiro.

Em 1998, a taxa de incidência da doença mantevese em patamares considerados reduzidos, se são tomados como parâmetros os valores observados nos dois anos epidêmicos, 1995 e 1996, mas seu valor de 65 casos por $100 \mathrm{mil}$ habitantes, foi superior ao alcançado em 1997. Os níveis das taxas também foram menores nos últimos meses do ano.

Observou-se em 1999, as mais baixas incidências de dengue durante o período deste estudo. Até a semana epidemiológica 42, haviam sido registrados 608 novos casos, e taxa de incidência de 16,2 por 100.000 habitantes. O valor máximo foi na semana 18 quando atinge 1,3 casos notificados por 100.000 habitantes.

No primeiro ano de epidemia, as áreas da cidade que apresentaram maiores riscos para esta doença foram os Distritos Sanitários Sanitários da Liberdade (1657,8 casos por 100.000 habitantes) e o Cabula/Beiru ( 882,8 por 100.000 habitantes) nos quais se situam muitos dos bairros carentes da cidade (Figura 2). No primeiro semestre do segundo ano, todas as áreas da cidade apresentaram altas incidências, com destaque para os Distritos Sanitários da Liberdade, Pau da Lima e Itapagipe, com incidências que variaram de aproximadamente 873 a 1560 por 100 mil habitantes.

Nos três primeiros anos deste estudo, a maior incidência de dengue foi entre os indivíduos com idade superior a 15 anos, principalmente, na faixa dos 20 aos 29 anos. Em 1998, este padrão se altera, sendo os menores de 10 anos, particularmente a faixa de 0 a 4 anos, os que apresentaram os maiores riscos (Figura 3). Entre 1995 e 1997, a incidência desta doença foi significativamente $(p=0,00)$ maior entre os indivíduos com idade igual ou superior a 15 anos que os menores de 15 anos $(0,21$ e 0,$86 ; 0,26$ e 0,58; 0,04 e 0,06 respectivamente). Em 1998 esta distribuição se inverte $(0,06$ e 0,04 respectivamente; $p=0,00)$.

No início da epidemia não se dispunha de dados sobre os IIP da maioria dos bairros de Salvador e entre aqueles para os quais existia registro desta informação, $53,1 \%$ estavam infestados e em $25,5 \%$ deles os IIP encontravam-se acima de $2 \%$. 


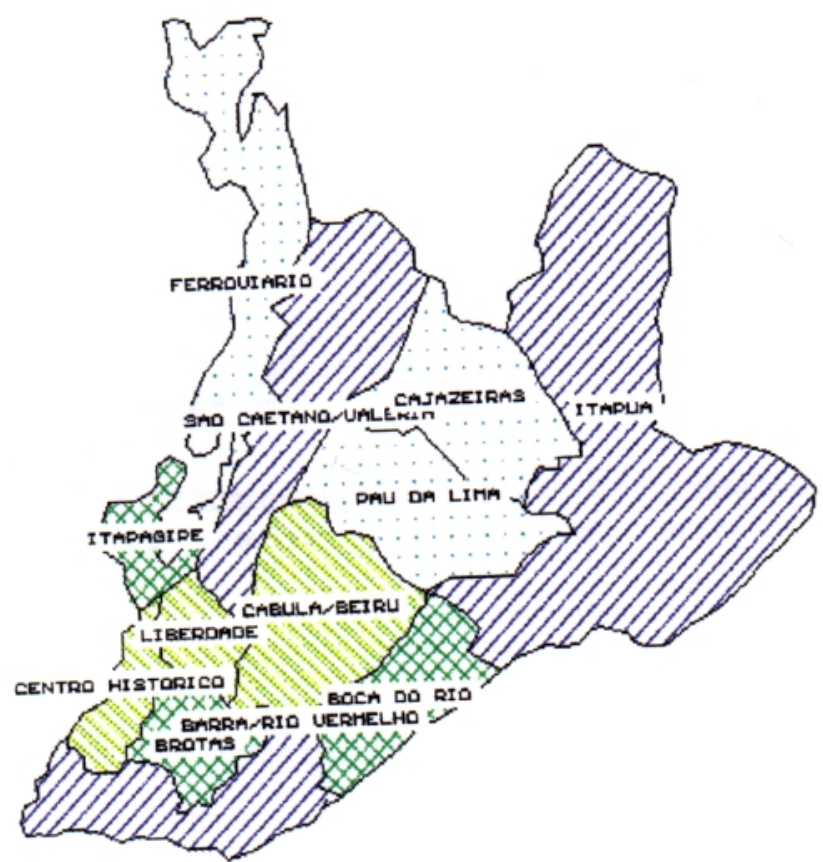

incidmanio $0 / 100.000$

$\therefore 108.69$ a 489.56

V74 489.57 a 663.5

ख 663.51 a 882.81

882.82 a 1657.85

Fonte: SESAB/DIVEP

Figura 2 - Incidência de casos notificados de dengue de acordo com distritos sanitários, Salvador - Bahia, 1995.

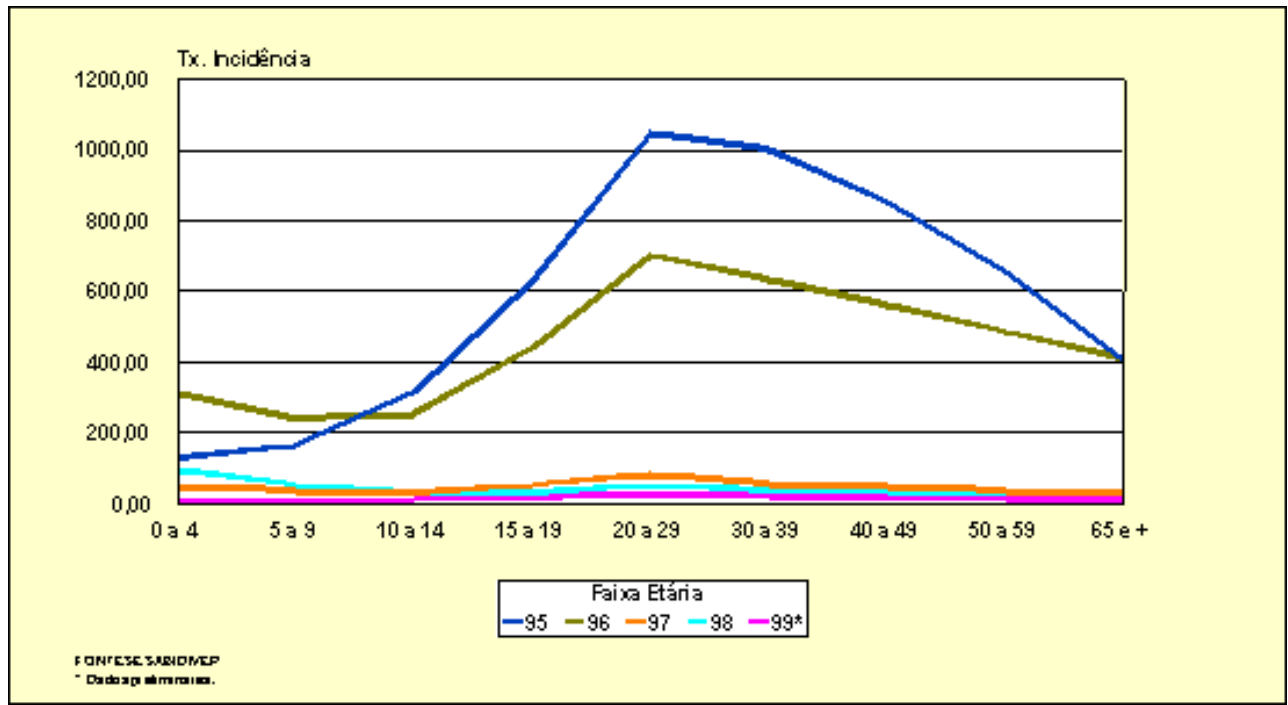

Figura 3 - Incidência de casos notificados de dengue (por 100.000 hab.) por faixa etária, Salvador Băhia, 1995 - 1999.

Em fevereiro de 1997, um levantamento deste índice (10 ciclo) foi feito em 141 bairros da cidade correspondendo a $70,7 \%$ do total existentes (208). Apenas três não se mostraram infestados pelo Aedes aegypti e cinco apresentaram IIP abaixo de $2 \%$. Excluindo-se os bairros não infestados observou-se uma grande variabilidade desses índices (0,3\% a 54,1\%), sendo a média de $12,6 \%$ e mediana de $11,75 \%$.
O IIP médio encontrado no levantamento realizado em 119 bairros em 1998, foi de 6,5\% e a mediana de $4,9 \%$. Os valores variaram de $24,7 \%$ a $0,3 \%$, excetuando-se seis bairros onde não foram detectadas formas imaturas de Aedes aegypti. Em apenas 14 bairros o IIP estava abaixo de $2 \%$.

No levantamento que se procedeu em janeiro de 1999, em somente 81 bairros onde foram desenvolvidas 
atividades de combate vetorial ( $39 \%$ dos existentes), encontrou-se um IIP médio de 6,3\% (variando de 0,6\% a $26,2 \%$ ) e mediana de 5,8\%. Em junho deste mesmo ano ( $3^{\circ}$ ciclo), a média foi de $5,8 \%$ e mediana $5 \%$. Não se encontrou nenhum bairro negativo e só em sete o IIP foi inferior a $2 \%$.

\section{DISCUSSÃO}

A introdução do vírus do dengue em Salvador em 1995 produziu neste e no ano seguinte duas ondas epidêmicas de grande magnitude da forma clássica da doença, padrão este semelhante ao de muitas capitais brasileiras em anos anteriores ${ }^{3}$. Embora o risco destas epidemias já fosse previsto em razão da intensa circulação dos sorotipos DEN-1 e DEN-2 em outros centros urbanos do país, não foi desenvolvida uma intervenção capaz de impedir estas ocorrências. As ações de combate ao Aedes aegyptique vinham sendo implementadas na cidade eram inexpressivas, pois o número de agentes de saúde disponíveis para este programa de controle era de apenas 197, quando se estimava ser necessário 1637, considerando-se a situação entomológica apontada no levantamento parcial de IIP, realizado naquele ano ${ }^{812}$.

Estas ondas epidêmicas iniciaram no mês de dezembro, sugerindo que a circulação viral está estreitamente relacionada com o início da estação mais quente do ano e que a transmissão do agente pode ter sido iniciada meses antes mesmo de ser detectada pela vigilância epidemiológica. Como houve um surto de rubéola em 1994, pode-se aventar a hipótese de que casos de dengue tenham sido confundidos com esta doença ${ }^{9}$. Além disso, embora o diagnóstico com comprovação laboratorial dos primeiros casos de dengue em Salvador tenha sido feito em janeiro de 1995, 14 casos foram confirmados em dezembro de 1994, retrospectivamente, mediante história clínica e vínculo epidemiológico, o que fortalece esta hipótese.

As curvas delineadas pelas duas epidemias mostraram-se diferentes em magnitude e forma. Em 1995, o pico concentrou-se em abril e maio, pois a circulação viral foi se estabelecendo na cidade nos primeiros meses do ano e a inexistência de imunidade de grupo propiciou a explosão da epidemia. Em 1996, após já ter se estabelecido uma parcial imunidade de grupo, as taxas de incidência não alcançaram os mesmos patamares do ano anterior. Este comportamento, não pode ser atribuído a medidas de combate vetorial, já que estas ações eram praticamente inexistentes, nem à subnotificação, pois o sistema de informações para dengue foi intensificado na rede de serviços de saúde e a população estava alerta devido ao desencadeamento de ações especiais de educação e informação em saúde. Estas foram desenvolvidas de forma articulada ou independente pelo conjunto de instituições responsáveis pela área de saúde pública da cidade ${ }^{111314}$ mas, por não terem sido acompanhadas de combate direto ao transmissor, possivelmente não contribuíram para a redução da população de mosquitos, conforme pode ser constatado no levantamento de IIP realizado em janeiro de $1997^{15}$.
O decréscimo da incidência observado entre as duas curvas epidêmicas em Salvador retrata a sazonalidade da doença no Brasil ${ }^{17}$, decorrente da redução da densidade da população de vetores em função da queda de temperatura e umidade que se registra entre julho e outubro, particularmente na Região Nordeste.

As oscilações nas incidências do final do mês de dezembro, podem estar associadas a menor demanda aos serviços de saúde devido as festas natalinas, fazendo com que as taxas de sub notificação se elevem. $\mathrm{Da}$ mesma forma, a redução de incidência correspondente às últimas semanas do mês de junho, pode ser imputada às festas juninas, quando é tradição, no nordeste brasileiro, a população deslocar-se da capital para o interior do Estado.

Nos anos que se seguiram às duas epidemias, as taxas de incidência de dengue reduziram-se, exceto no mês de abril de 1997. É importante destacar que foi em março deste ano que foi isolado o sorotipo DEN-1 na cidade, mas é possível que este sorotipo já estivesse circulando anteriormente em Salvador.

Apesar de, nas duas ondas epidêmicas, as áreas mais afetadas terem sido as mais densamente povoadas onde se concentra parte da população carente da cidade (Distritos Sanitários da Liberdade e Cabula/Beiru), é possível que suas elevadas taxas de incidência não representem um risco desigual de acometimento da doença em função das diferentes características sócio econômicas de sua população, mas sim o reflexo do viés das notificações, pois cerca de $90 \%$ destes registros são oriundos de unidades públicas da rede de serviços de saúde (SINAN), que atendem com maior freqüência camadas mais pobres da população.

Não se tem um comportamento único de ocorrência por idade no dengue, entretanto, a maior incidência da doença nas faixas etárias mais elevadas é um padrão observado em áreas indenes logo após a introdução de um sorotipo do vírus ${ }^{6}{ }^{7}$, como a que foi observada neste estudo e em um inquérito sorepidemiológico realizado em São Luís do Maranhão ${ }^{20}$, área de circulação viral recente. Em geral, este padrão se modifica na medida em que se instala o processo de endemização da doença. A diferença nas faixas etárias encontrada em 1998, já está apontando nesta direção.

Em muitos países as ações de combate ao Aedes aegypti vêm apresentado baixa efetividade ${ }^{56}$, devido à complexidade da biologia deste vetor e sua capacidade de adaptação ao ambiente humano, além de dificuldades técnicas e operacionais para execução das atividades para se alcançar níveis de infestação 
compatíveis com a eliminação da transmissão, que devem ser zero ou muito próximos a zero. Circulação viral tem sido estabelecida mesmo em situações de densidade próximas a $1 \%$ de IIP 5 . Em Salvador, o insucesso das ações de combate vetorial parecem estar mais relacionadas a problemas operacionais. Tais ações só foram intensificadas em 1997, após o estabelecimento da transmissão viral e da ocorrência das epidemias. Ademais, o programa não implantou os componentes de saneamento, educação e informação em saúde conforme preconizados no Plano Diretor de Erradicação do Aedes aegypti do Brasil ${ }^{4}$, e as atividades desenvolvidas referem-se quase exclusivamente ao combate químico e físico ao mosquito, sem caráter universal pois, não abrangem todos os espaços do território de Salvador, nem sempre cumprem os ciclos de trabalho no tempo adequado e sofrem solução de continuidade em virtude de não haver repasse automático de recursos financeiros ${ }^{16}$.

A decisão dos dirigentes do Programa de Erradicação em Salvador de beneficiar parte dos bairros da cidade e fazer um esforço para cumprir todas as atividades dentro do período estabelecido para cada ciclo de trabalho, vem resultando em uma gradativa redução dos IIP destas áreas, como pode ser observado em 199916. Entretanto, a situação entomológica das outras áreas não cobertas pelas ações programáticas podem estar contribuindo para a lentidão na redução destes índices e mesmo para sua elevação em alguns bairros onde as ações são desenvolvidas, devido à grande mobilidade do vetor.

A ocorrência de casos desta doença pelos sorotipos DEN-1 e DEN-2 durante todos os meses dos últimos anos, mesmo com baixa incidência, indica que estes agentes estão circulando já sob a forma endêmica na cidade. Entretanto, a diminuição da morbidade não pode ser imputada apenas a redução dos IIP conseqüente às ações de combate vetorial. Tem-se que considerar que a imunidade de grupo para estes sorotipos que foi estabelecida na cidade desempenha um importante papel neste processo.

Entende-se que a estratégia de combate vetorial adotada não vem favorecendo a obtenção do impacto epidemiológico desejado, que é o de interrupção da circulação dos vírus circulante, e nem mesmo assegura a redução do risco de introdução de outros sorotipos do vírus do dengue. Os níveis de infestação do mosquito que hoje são registrados em Salvador, ao contrário, apontam para a possibilidade de ocorrência de novas epidemias, inclusive com formas graves da doença.

\section{REFERÊNCIAS BIBLIOGRÁFICAS}

1. Castro JSM. Situação do dengue na Bahia. Boletim Epidemiológico 5: 2-15, 1999.

2. Dias JR. Relatório sobre a situação de dengue no Estado da Bahia. Revista Baiana de Saúde Pública 22:49-67, 1997.

3. Donalísio MRC. O enfrentamento de epidemias: as estratégias e perspectivas do controle do dengue. Tese de Doutorado. Campinas, 1995.

4. Fundação Nacional de Saúde. Ministério da Saúde. Plano Diretor de Erradicação do Aedes aegypti do Brasil. Brasília, 1996.

5. Goh KT. Changing epidemiology of dengue in Singapore. The Lancet. 346: 1098, 1995.

6. Gubler DJ. Dengue and dengue hemorrhagic fever: its history and resurgence as a global health problem. In: Gubler DJ, Kuno G (eds) Dengue and dengue hemorrhagic fever. CAB International, New York p.1-22, 1997.

7. Halstead SB. Epidemiology of dengue and dengue hemorrhagic fever In: Gubler DJ, Kuno G (eds) Dengue and dengue hemorrhagic fever. CAB International, New York p. 23-44, 1997.

8. Instituto de Saúde Saúde Coletiva/Universidade Federal da Bahia. Projeto piloto para erradicação do Aedes aegypti Salvador-Bahia. Salvador, 1996.

9. Secretaria da Saúde/Departamento de Vigilância da Saúde/ Divisão de Vigilância Epidemiológica. III Informe epidemiológico sobre Dengue, 1995.

10. Secretaria da Saúde/Departamento de Informação e Comunicação em Saúde. Sistema Nacional de Agravos de Notificação (SINAN), 1995 - 2000.

11. Secretaria Municipal de Saúde Relatório anual de atividades. Prefeitura Municipal de Salvador, 1995.

12. Secretaria Municipal de Saúde. Centro de Controle de Zoonozes. Plano de Intensificação de Combate ao Aedes aegyptino Município de Salvador. Prefeitura Municipal de Salvador, 1996.
13. Secretaria Municipal de Saúde. Relatório anual de atividades. Prefeitura Municipal de Salvador, 1996.

14. Secretaria Municipal de Saúde. Plano municipal de saúde 19982001. Prefeitura Municipal de Salvador, 1997.

15. Secretaria Municipal de Saúde. Centro de Controle de Zoonozes Relatório parcial das ações do plano de combate ao Aedes aegypti. Prefeitura Municipal de Salvador, 1998.

16. Secretaria Municipal de Saúde. Centro de Controle de Zoonozes, Plano de Erradicação do Aedes aegypti no Município de Salvador. Relatório do $3^{\circ}$ Ciclo de 1999. Prefeitura Municipal de Salvador, 1999.

17. Silveira AC. Dengue: aspectos epidemiológicos e de controle. Revista da Sociedade Brasileira de Medicina Tropical 31 (supl II): 5-14, 1998.

18. Teixeira MG, Barreto ML, Porque devemos, de novo, erradicar o Aedes aegypti. Ciência \& Saúde Coletiva 1:122-135, 1996.

19. Teixeira MG, Barreto ML, Guerra Z. Epidemiologia e medidas de prevenção do dengue. Informe Epidemiológico do Sistema Único de Saúde 8: 5-33, 1999.

20. Vasconcelos PFC, Lima JW, Raposo ML, Rodrigues S.G, Travassos da Rosa JFS, Amorim SMC, Travassos da Rosa ES, Moura CMP, Fonseca AN, Travassos da Rosa PA. Inquérito soroepidemiológico na llha de São Luís durante epidemia de dengue no Maranhão. Revista da Sociedade Brasileira de Medicina Tropical 32:171-179, 1999.

21. Vasconcelos PFC, Mota K, Travassos da Rosa A, Tavares Neto J. Epidemia de dengue em Ipupiara e Prado, Bahia: inquérito soroepidemiológico. Revista Sociedade Brasileira de Medicina Tropical 33: 61-67, 2000. 